\title{
Long-Term Prognosis of Japanese Patients with Crohn's Disease Treated by Switching Anti-Tumor Necrosis Factor-a Antibodies
}

\author{
Rintaro Moroi ${ }^{a}$ Hisashi Shiga $^{a}$ Katsuya Endo $^{b}$ Katsutoshi Yamamoto $^{a}$ \\ Masatake Kuroha ${ }^{a}$ Yoshitake Kanazawa $^{a}$ Yoichi Kakuta ${ }^{a}$ Yoshitaka Kinouchi $^{a}$ \\ Atsushi Masamune ${ }^{a}$ \\ a Division of Gastroenterology, Department of Internal Medicine, Tohoku University Graduate School of Medicine, \\ Sendai, Japan; 'bivision of Gastroenterology and Hepatology, Tohoku Medical and Pharmaceutical University, \\ Sendai, Japan
}

\section{Keywords}

Crohn's disease · Anti-tumor necrosis factor-a antibodies ·

Prognosis

\begin{abstract}
Introduction: The long-term prognosis of Japanese patients with Crohn's disease (CD) treated by switching anti-tumor necrosis factor-a (anti-TNFa) antibodies remains unclear. Objective: This study aimed to clarify the long-term prognosis and clinical factors that affect the long-term prognosis and outcomes of such patients. Methods: This retrospective, observational, single-center cohort study analyzed Japanese patients with $C D$ treated by switching between infliximab and adalimumab in the Tohoku University Hospital between March 2003 and December 2017. Cumulative relapse-free survival and cumulative surgery-free survival rates were analyzed using the Kaplan-Meier method. Clinical factors that affected the long-term outcomes were identified using both a log-rank test and the Cox proportional hazards model. $\boldsymbol{R} \boldsymbol{e}$ sults: The cumulative relapse-free survival rates were 68.6, 33.7 , and $22.9 \%$ at 1,3 , and 5 years, respectively. The surgeryfree survival rates were $91.7,75.7$, and $57.4 \%$ at 1,3 , and 5 years, respectively. The cumulative relapse-free survival rate was significantly higher in the group with ileal lesions ( $\mathrm{HR}=$
\end{abstract}

\begin{tabular}{ll}
\hline KARGER & ( 2019 The Author(s) Karger \\
& Published by S. Karger AG, Basel Open access \\
E-Mail karger@karger.com & This article is licensed under the Creative Commons Attribution- \\
www.karger.com/iid & $\begin{array}{l}\text { NonCommercial-NoDerivatives 4.0 International License (CC BY- } \\
\text { NC-ND) (http://www.karger.com/Services/OpenAccessLicense). } \\
\text { Usage and distribution for commercial purposes as well as any dis- } \\
\text { tribution of modified material requires written permission. }\end{array}$
\end{tabular}

$0.12 ; 95 \% \mathrm{Cl} 0.0066-0.64, p=0.0086)$, stricture $(\mathrm{HR}=0.24$; $95 \% \mathrm{Cl} 0.0094-0.59, p=0.0021)$, and a penetrating type $(\mathrm{HR}=0.34 ; 95 \% \mathrm{Cl} 0.14-0.84, p=0.020)$. Intolerance $(\mathrm{HR}=$ $0.29 ; 95 \% \mathrm{Cl} 0.12-0.63, p=0.0013)$ and switching after surgery $(\mathrm{HR}=0.41 ; 95 \% \mathrm{Cl} 0.17-0.87, p=0.019)$ were clinical factors that reduced the risk of recurrence. The cumulative surgery-free survival rate was significantly higher in the group that switched after surgery $(\mathrm{HR}=0.28 ; 95 \% \mathrm{Cl} 0.074-$ $0.91, p=0.034)$ and used concomitant thiopurine $(H R=0.32$; $95 \% \mathrm{Cl} 0.10-0.90, p=0.030)$. Conclusion: We should clarify the reason for switching anti-TNFa antibodies and investigate bowel complications before switching. Surgical reset of bowel complications including stricture and fistula could reduce the risk of recurrence after switching anti-TNFa antibodies. Concomitant thiopurine administration might reduce the risk of bowel surgery after switching anti-TNFa antibodies.

(c) 2019 The Author(s)

Published by S. Karger AG, Basel

\section{Introduction}

Crohn's disease (CD) is a chronic bowel inflammatory disease with repeated cycles of exacerbation and remission. CD complications include bowel stenosis, fistula,
Rintaro Moroi, MD, PhD

Division of Gastroenterology, Department of Internal Medicine Tohoku University Graduate School of Medicine

1-1 Seiryo-cho, Aoba-ku, Sendai, Miyagi 980-8574 (Japan)

E-Mail rinta@med.tohoku.ac.jp 
and perforation, which ultimately require surgical resection [1]. Anti-tumor necrosis factor- $\alpha$ (anti-TNFa) antibodies (biologics), such as infliximab (IFX) and adalimumab (ADA), have drastically changed the therapeutic strategy for CD due to their high induction efficacy $[2,3]$. After induction of remission, these 2 biologics are also used as maintenance treatment for refractory CD with moderate to severe disease activity $[2,4-11]$. In Japan, induction and maintenance treatments with IFX and dose escalation of IFX were officially approved in May 2002, November 2007, and August 2011, respectively. In contrast, induction and maintenance treatments with ADA and dose escalation of ADA were also approved in October 2010 and June 2016, respectively.

Several studies have reported that, despite the use of maintenance biologics, CD relapse rates increased annually $[6,8,12-16]$. Those studies indicated that a loss of response (LOR = secondary failure) could occur despite appropriate administration of maintenance biologics in patients with CD. The estimated LOR rates of IFX and ADA were 13 and $20.3 \%$ per patient year, respectively [12, 13]. In case of LOR, several treatment options exist, including dose escalation, shortening of the interval of administration, and switching of biologics. In addition to the LOR, primary nonresponse and intolerance to biologics could also be causes of switching biologics. One systematic review reported that the clinical remission rate at 12 months after switching biologics ranged from 19 to $68 \%$ [17]. Another meta-analysis revealed that the remission rate after switching biologics depended on the reason the first biologics were withdrawn, such as intolerance (61\%), secondary failure (45\%), and primary failure (30\%) [18].

Although there are several reports in Western countries on the long-term prognosis after switching biologics, many aspects remain unknown. Furthermore, the longterm prognosis after switching biologics and the clinical factors associated with the long-term prognosis in Japanese patients with CD are unclear. The clinical $[19,20]$ and genetic [21] backgrounds of Asian patients with CD are different from those of patients from Western countries. Therefore, it is important to evaluate the prognosis of anti-TNFa treatments in Japanese patients. To improve the prognosis of Japanese patients with $\mathrm{CD}$ after switching biologics, the unknown factors described above should be clarified. Thus, in this study, we aimed to evaluate the long-term prognosis of Japanese patients with $\mathrm{CD}$ after switching biologics, to identify the clinical factors that affect the long-term prognosis after switching biologics, and to discuss the best optimization for switching biologics in these patients.

\section{Materials and Methods}

\section{Study Design}

This was a retrospective, observational cohort study at a single center. The study protocol was reviewed and approved by the Tohoku University Hospital Ethics Committee (2018-1-138).

\section{Patients}

We enrolled consecutive Japanese patients with CD who had a history of treatment with both IFX (Mitsubishi-Tanabe Pharma, Tokyo, Japan) and ADA (EA pharma, Tokyo, Japan) in Tohoku University Hospital between March 2003 and December 2017. We excluded patients whose medical records had incomplete data for the start or end date of using the first or second biologic and incomplete laboratory data due to start of the biologics at another hospital. CD was diagnosed via endoscopic and/or radiological and/or histological examination if the patients presented specific features including longitudinal ulcer, a cobblestone appearance, and noncaseous epithelioid cell granuloma [22].

\section{Protocol of Anti-TNFa Antibody Administration}

Anti-TNFa antibody treatments were administered to CD patients with moderate to severe disease activity who had active luminal disease or active perianal disease. In patients with perianal fistula with abscess, drainage was performed. Anti-TNFa antibodies are not indicated for CD patients with severe strictures or internal fistulas; surgical operation was performed for such complications.

During the induction phase of IFX treatment, $5 \mathrm{mg} / \mathrm{kg}$ of IFX was administered at weeks 0,2 , and 6 . Subsequently, as maintenance therapy, $5 \mathrm{mg} / \mathrm{kg}$ of IFX was administered every 8 weeks. With regard to the induction phase of ADA treatment, $160 \mathrm{mg}$ of ADA was injected subcutaneously at week 0 . At week 2 , a dose of $80 \mathrm{mg}$ was administered subcutaneously. After week 4, a dose of $40 \mathrm{mg}$ was administered every 2 weeks subcutaneously. Patients who were given either biologic dose escalation were deemed to have an LOR. Ustekinumab and vedolizumab were not approved at that time.

\section{Evaluation of the Long-Term Prognosis of Maintenance}

\section{Treatment}

We reviewed the medical records of all of the enrolled patients and evaluated the cumulative relapse-free survival rate (end point: clinical relapse) and the surgery-free survival rate (end point: operation) using the Kaplan-Meier method. Following the preceding study, clinical relapse was defined as the need for additional, internal treatment (e.g., steroids, thiopurine, dose escalation, or a shortened time interval of the biologics), hospitalization due to worsening of $\mathrm{CD}$, or surgery. Most of the patients who were given biologics visited our hospital every month, and the disease status of the patients was assessed at that time.

Concomitant thiopurine was defined as simultaneous use of thiopurine at the start of switching biologics. Starting thiopurine after biologic administration was regarded as relapse. Thiopurines were administered at $25-50 \mathrm{mg} /$ day in most of cases. Thiopurine doses were optimized by monitoring the white blood cell counts that should be adjusted within 3,000-4,000/ $\mu \mathrm{L}$. In several cases, the dose was increased to $100 \mathrm{mg} /$ day. Both thiopurine and an elemental diet were continued during biologic administration unless adverse events occurred.
Moroi et al. 
Table 1. Clinical characteristics of the study population

\begin{tabular}{lc}
\hline Characteristic & Total $n=69$ \\
\hline Male/female ratio & $45 / 24$ \\
Age at diagnosis & $22.5 \pm 8.2$ \\
Disease duration with switching biologics, years & $13.9 \pm 8.5$ \\
Disease location (ileal/ileocolonic/colonic) & $4 / 52 / 13$ \\
Disease phenotype (nonstricturing, nonpenetrating/stricturing/penetrating) & $18 / 28 / 23$ \\
Anal lesion & $52(75.4)$ \\
History of surgery & $47(68.1)$ \\
Switch order (IFX to ADA/ADA to IFX) & $62 / 7$ \\
Switch after surgery & $16(23.1)$ \\
Concomitant therapy & \\
$\quad$ 5ASA & $43(62.3)$ \\
Steroid & $16(23.1)$ \\
$\quad$ Elemental diet & $20(29.0)$ \\
$\quad$ Thiopurine & $29(42.0)$ \\
\hline
\end{tabular}

Values are presented as means \pm SD or numbers (\%) unless otherwise stated. 5ASA, 5-aminosalicylic acid.

Table 2. Comparison of orders of switching biologics

\begin{tabular}{lrr}
\hline Characteristic & IFX to ADA & ADA to IFX \\
\hline Cases, $n$ & 62 \\
Median duration of the first biologic administration, months & 22.8 & 7 \\
Median time to switch of biologics after discontinuation of the first biologic, months & 3 & 21.5 \\
Dose escalation of the first biologic & 10 \\
Reason for switch, $n$ (\%) & $17(27.4)$ \\
$\quad$ Intolerance & $7(11.3)$ \\
$\quad$ Primary failure & $38(61.3)$ \\
$\quad$ Secondary failure & $15(24.2)$ \\
Switch after surgery & 0.7 \\
\hline
\end{tabular}

Identification of Factors Associated with Long-Term Outcomes The association between clinical factors and long-term prognosis was analyzed using a log-rank test. The estimated clinical factors were sex, lesion location, disease behavior, switch after surgery, reason for switching biologics, concomitant thiopurine, and presence of anal lesions. Multivariate analysis was performed using the Cox proportional hazards model to identify independent risk factors that affected relapse and surgery.

Statistics

$p<0.05$ was considered statistically significant. All analyses were performed using JMP Pro11 software (SAS Institute, Tokyo, Japan).

\section{Results}

\section{Patient Characteristics}

In this study, we first enrolled 83 patients, 14 of whom were excluded due to issues with clinical data. Finally, long-term outcomes were analyzed in 69 cases (IFX, $n=$ $62 ; 89.9 \%)$ and ADA $(n=7 ; 10.1 \%)$. Seventeen patients were treated with dose escalation of IFX. No patient had a shortened interval of IFX administration or dose escalation of ADA. The baseline characteristics of the patients are summarized in Table 1 . The average age at $C D$ diagnosis was 22.5 years. The average disease duration was 13.9 years. The identified disease locations were as follows: ileal, $n=4$; ileocolonic, $n=52$; and colonic, $n=$ 13. As for disease behavior, 18, 28 and 23 patients had nonstricturing/nonpenetrating, stricturing, and penetrating types. Fifty-two patients (75.4\%) had anal lesions, and 47 patients $(68.1 \%)$ had a history of intestinal resection. Concomitant therapies were as follows: treatment with 5-aminosalicylic acid, $n=43(62.3 \%)$; treatment with steroids, $n=16$ (23.1\%); elemental diet, $n=20$ (29.0\%); and treatment with thiopurine, $n=29$ (42.0\%). 


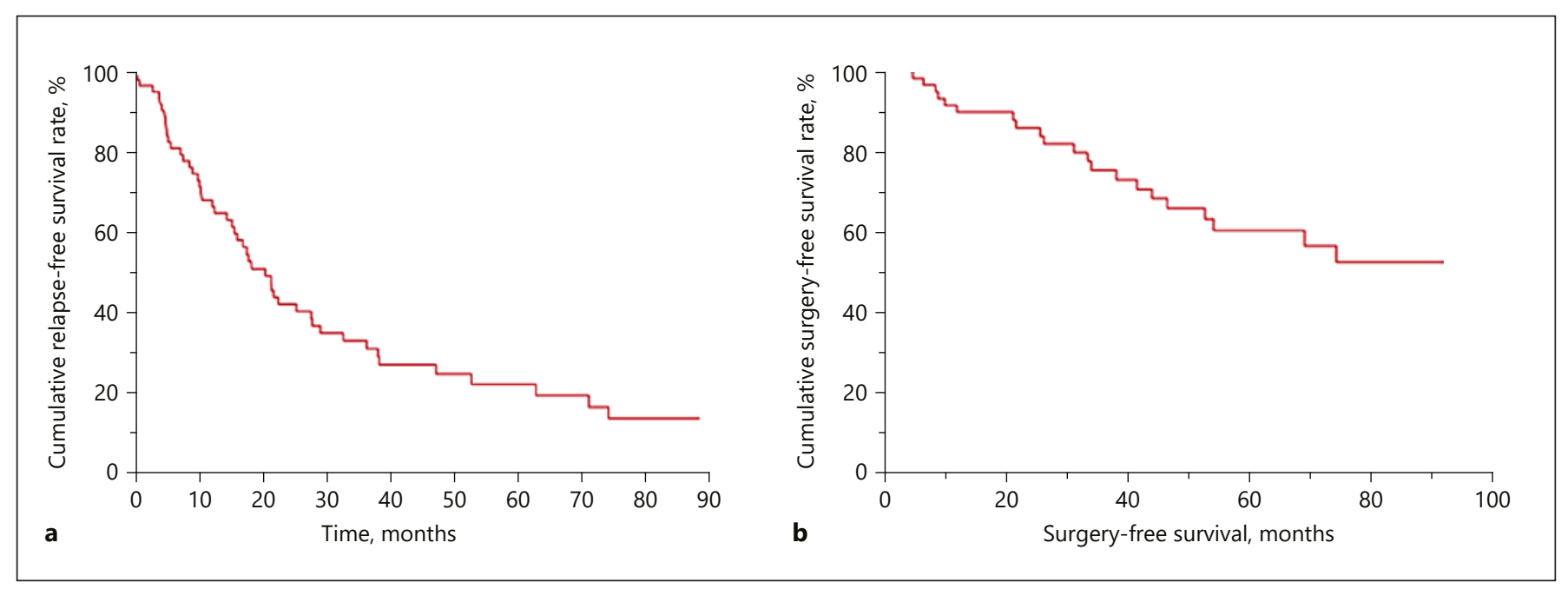

Fig. 1. Overall long-term prognosis after switching biologics. a The cumulative relapse-free survival rates were $68.6,33.7$, and $22.9 \%$ at 1,3 , and 5 years, respectively. b The cumulative surgery-free survival rates were 91.7 , 75.7 , and $57.4 \%$ at 1,3 , and 5 years, respectively.

The median duration of switching biologics after surgery was 41 days.

Sixty-two patients switched from IFX to ADA, while 7 patients switched oppositely. The differences between the 2 groups (IFX to ADA and ADA to IFX) are summarized in Table 2.

\section{Overall Long-Term Prognosis}

Of the patients, 25 had recurrence and 21 underwent bowel resection due to worsening $\mathrm{CD}$ during their clinical course. The rates of cumulative relapse-free survival and surgery-free survival are shown in Figure 1. The cumulative relapse-free survival rates were 68.6, 33.7, and $22.9 \%$ at 1,3 , and 5 years, respectively. The surgery-free survival rates were $91.7,75.7$, and $57.4 \%$ at 1,3 , and 5 years, respectively.

No differences in the rates of cumulative relapse-free survival were found between the 2 groups (order of biologics use: IFX to ADA, ADA to IFX) (Fig. 2).

\section{Factors Associated with Long-Term Outcomes}

The association between clinical factors and cumulative relapse-free survival is summarized in Table 3 . The log-rank test revealed that cumulative relapse-free survival rates were significantly higher in patients with the ileal type (vs. ileocolonic and colonic, $p=0.044$ ) and stricturing and penetrating types (vs. nonstricturing/ nonpenetrating, $p=0.0012$ ) and those who switched after surgery (vs. switch without surgery, $p=0.017$ ). The differences in the Kaplan-Meier curves of the cumula-

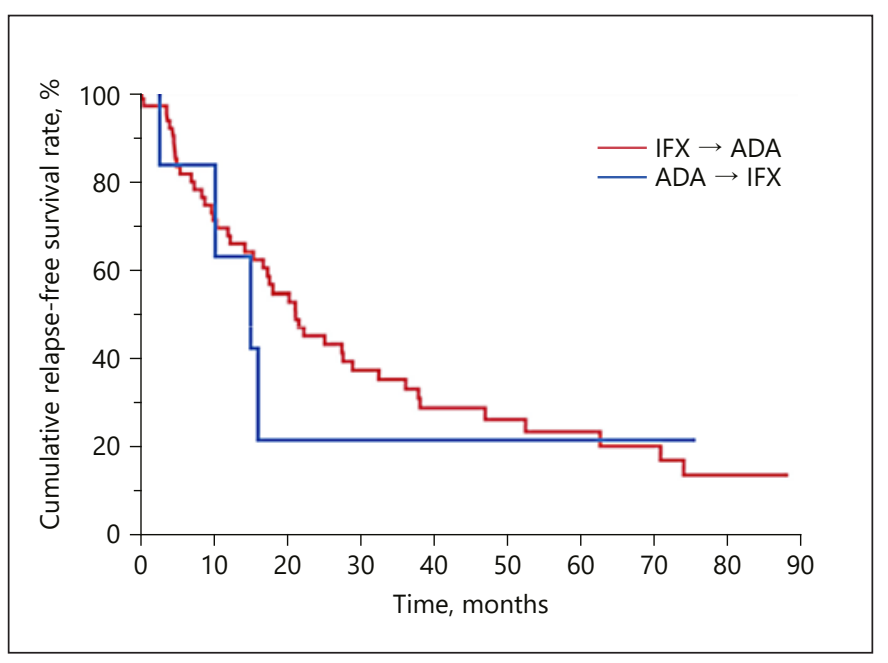

Fig. 2. Comparison of cumulative relapse-free survival rate in order of biologics. No difference was found between the 2 groups (infliximab to adalimumab, adalimumab to infliximab).

tive relapse-free survival rates of the biologics, for each clinical factor identified by log-rank test, are shown in Figure 3. In the multivariate analysis, ileal type $(\mathrm{HR}=$ 0.12 ; 95\% CI $0.015-0.98, p=0.047)$, stricturing ( $\mathrm{HR}=$ 0.24 ; $95 \%$ CI $0.095-0.58, p=0.0018)$, penetrating $(\mathrm{HR}=$ 0.34 ; $95 \%$ CI $0.14-0.83, p=0.018)$, switch after surgery $(\mathrm{HR}=0.41 ; 95 \%$ CI $0.18-0.89, p=0.025)$, and intolerance $(\mathrm{HR}=0.29 ; 95 \%$ CI $0.13-0.66, p=0.0032)$ were identified as clinical factors that reduced the risk for recurrence (Table 3). 
Table 3. Summary of the association between clinical factors and long-term outcomes (relapse-free survival)

\begin{tabular}{|c|c|c|c|c|c|}
\hline \multirow[t]{2}{*}{ Clinical factor } & \multirow{2}{*}{$\begin{array}{l}\text { Patients, } \\
n\end{array}$} & \multirow{2}{*}{$\begin{array}{l}\begin{array}{l}\text { Univariate } \\
\text { analysis }^{\mathrm{a}}\end{array} \\
p \text { value }\end{array}$} & \multicolumn{3}{|c|}{ Multivariate analysis ${ }^{\mathrm{b}}$} \\
\hline & & & HR & $95 \% \mathrm{CI}$ & $p$ value \\
\hline \multicolumn{6}{|l|}{ Sex } \\
\hline Male & 45 & 0.92 & 1.03 & $0.52-2.01$ & 0.92 \\
\hline Female & 24 & & 1 & & \\
\hline \multicolumn{6}{|l|}{ Disease location } \\
\hline Ileal & 4 & 0.044 & 0.12 & $0.015-0.98$ & 0.047 \\
\hline Colonic & 13 & & 0.65 & $0.25-1.52$ & 0.33 \\
\hline Ileocolonic & 52 & & 1 & & \\
\hline \multicolumn{6}{|l|}{ Disease behavior } \\
\hline Stricturing & 28 & 0.0012 & 0.24 & $0.095-0.58$ & 0.0018 \\
\hline Penetrating & 23 & & 0.34 & $0.14-0.83$ & 0.018 \\
\hline Nonstricturing/nonpenetrating & 18 & & 1 & & \\
\hline \multicolumn{6}{|l|}{ Anal disease } \\
\hline No & 17 & 0.28 & 1.86 & $0.87-4.06$ & 0.12 \\
\hline Yes & 52 & & 1 & & \\
\hline \multicolumn{6}{|l|}{ Switch after surgery } \\
\hline Yes & 16 & 0.017 & 0.41 & $0.18-0.89$ & 0.025 \\
\hline No & 53 & & 1 & & \\
\hline \multicolumn{6}{|l|}{ Concomitant thiopurine } \\
\hline Yes & 29 & 0.75 & 0.74 & $0.38-1.44$ & 0.37 \\
\hline No & 40 & & 1 & & \\
\hline \multicolumn{6}{|l|}{ Reason for the switch } \\
\hline Intolerance & 17 & 0.085 & 0.29 & $0.13-0.66$ & 0.0032 \\
\hline Primary failure & 7 & & 0.56 & $0.21-1.54$ & 0.26 \\
\hline Secondary failure & 45 & & 1 & & \\
\hline
\end{tabular}

${ }^{\mathrm{a}}$ Log-rank test. ${ }^{\mathrm{b}}$ Cox proportional hazards model.

The association between clinical factors and cumulative surgery-free survival, analyzed using the log-rank test and the Cox proportional hazard model, is summarized in Table 4. No clinical factors affecting surgery-free survival were found using the log-rank test.

On multivariate analysis, switch after surgery $(\mathrm{HR}=$ 0.29 ; 95\% CI $0.0084-0.99, p=0.048$ ) and concomitant thiopurine ( $\mathrm{HR}=0.32$; 95\% CI $0.11-0.94, p=0.039$ ) were also identified as clinical factors that reduce the risk for surgery.

\section{Discussion}

In this study, we investigated the long-term prognosis of Japanese patients with CD who changed their biologics due to various reasons. The cumulative relapse-free and surgery-free survival rates decreased annually. We also investigated clinical factors that affect the long-term prognosis. Multivariate analysis revealed that ileal type, stricturing and penetrating types, switch after surgery, and intolerance were clinical factors that reduced the risk for recurrence. Similarly, switching after surgery and concomitant thiopurine were detected as clinical factors that reduces the risk for resurgery.

Although several meta-analysis reports are available $[17,18]$, there is little evidence regarding the long-term prognosis of patients with CD who switched their biologics for various reasons. There is only 1 case series of Japanese patients with CD who switched from ADA to IFX [23]. To our knowledge, this is the first report investigating the long-term prognosis and clinical factors that affect the prognosis after switching biologics in Japanese patients with CD.

This study showed that the cumulative relapse-free survival rates were decreased annually in patients who switched biologics as well as in biologic-naive patients. We previously reported that the cumulative relapse-free survival rate of biologic-naive Japanese patients with CD decreased annually [16]. The cumulative relapse-free sur- 


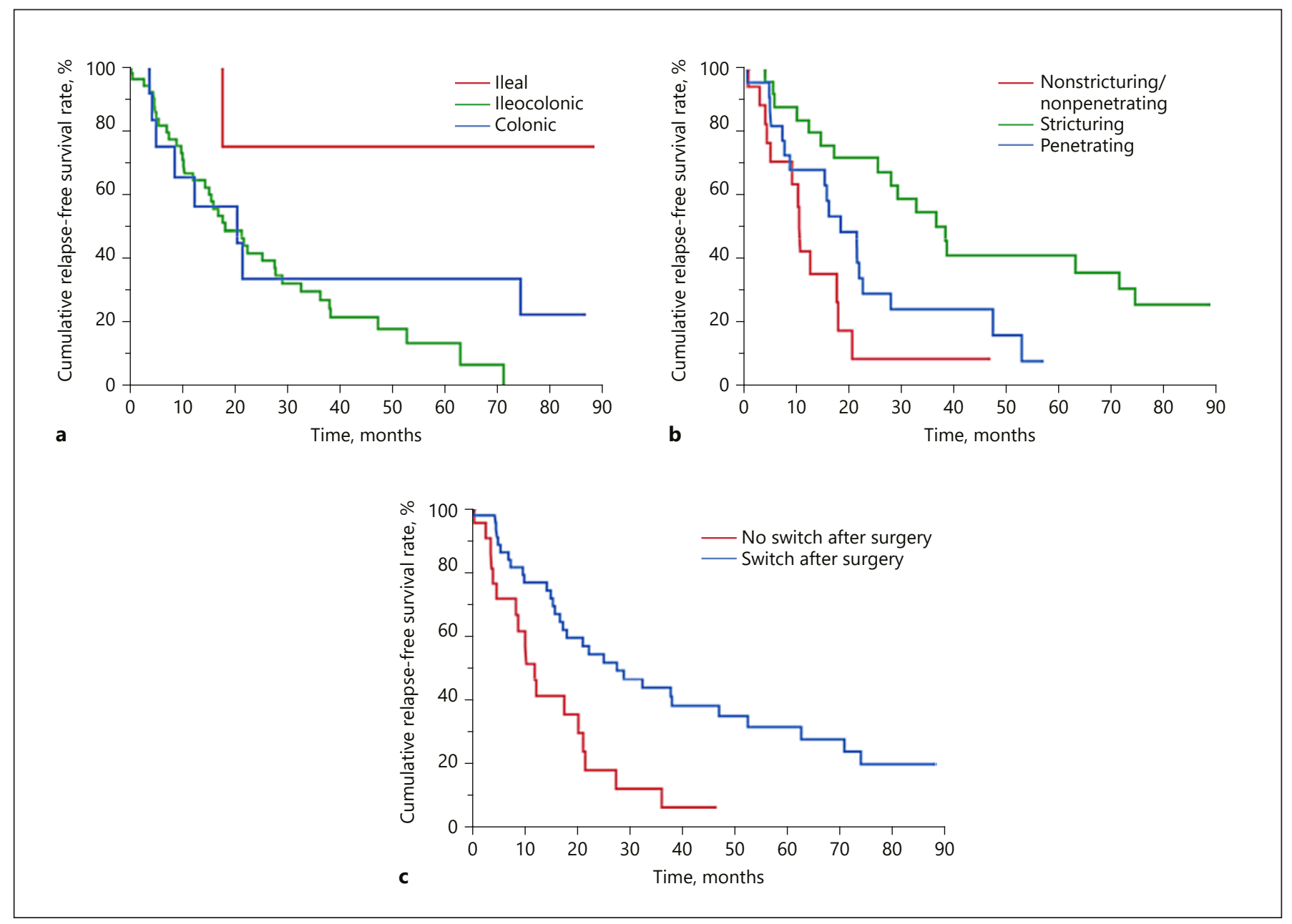

Fig. 3. Differences in cumulative relapse-free survival rates for each clinical factor. a The Kaplan-Meier curves show the cumulative relapse-free survival rates according to disease location. The cumulative relapse-free survival rate was significantly higher in the ileal type than in the other types. b The Kaplan-Meier curves show the cumulative relapse-free survival rates according to disease behavior. The cumulative relapse-free survival rate was significantly

vival rates of biologic-naive Japanese patients with $\mathrm{CD}$ were 80,54 , and $39 \%$ at 1,3 , and 5 years, respectively. However, the cumulative relapse-free survival rates in this study were $68.6,33.7$, and $22.9 \%$ at 1,3 , and 5 years, respectively. As expected, our results revealed that the cumulative relapse-free survival rate of the second biologic was lower than that of the first biologic. These results were consistent with 2 systematic reviews $[17,18]$.

Several studies have shown that patients who have antibodies to IFX easily develop antibodies to ADA compared to patients who have no antibodies to IFX $[24,25]$. More frequent development of anti-drug antibodies after switch- higher in the stricturing and penetrating type than in the nonstricturing/nonpenetrating type. $\mathbf{c}$ The Kaplan-Meier curves show the cumulative relapse-free survival rates according to switching after surgery or not switching after surgery. The cumulative relapse-free survival rate was significantly higher in patients who switched after surgery than in those who did not. ing biologics is considered to be a reason for the worse result of the second biologic. In contrast, a study reported that antibodies to ADA do not cross-react with IFX [26]. Therefore, the lower development of anti-drug antibodies could be a main strategy for efficient switching of biologics. With regard to concomitant immunomodulators, a sub-analysis of the DIAMOND study revealed that higher 6-thioguanine nucleotide levels tended to be negative for anti-ADA antibodies [27]. Two other studies revealed significantly improved outcomes following combination treatment with IFX and thiopurines, both in the induction phase and in the maintenance phase $[15,28]$. These studies indicated that 
Table 4. Summary of the association between clinical factors and long-term outcomes (surgery-free survival)

\begin{tabular}{|c|c|c|c|c|c|}
\hline \multirow[t]{2}{*}{ Clinical factor } & \multirow{2}{*}{$\begin{array}{l}\text { Patients, } \\
n\end{array}$} & \multirow{2}{*}{$\begin{array}{l}\begin{array}{l}\text { Univariate } \\
\text { analysis }^{\mathrm{a}}\end{array} \\
p \text { value }\end{array}$} & \multicolumn{3}{|c|}{ Multivariate analysis ${ }^{\mathrm{b}}$} \\
\hline & & & $\mathrm{HR}$ & $95 \% \mathrm{CI}$ & $p$ value \\
\hline \multicolumn{6}{|l|}{ Sex } \\
\hline Male & 45 & \multirow[t]{2}{*}{0.23} & 2.11 & \multirow{2}{*}{$0.66-6.74$} & \multirow{2}{*}{0.20} \\
\hline Female & 24 & & 1 & & \\
\hline \multicolumn{6}{|l|}{ Disease location } \\
\hline Ileal & 4 & \multirow[t]{3}{*}{0.48} & 0.84 & $0.093-7.61$ & 0.88 \\
\hline Colonic & 13 & & 1.21 & \multirow[t]{2}{*}{$0.224-6.14$} & \multirow[t]{2}{*}{0.81} \\
\hline Ileocolonic & 52 & & 1 & & \\
\hline \multicolumn{6}{|l|}{ Disease behavior } \\
\hline Stricturing & 28 & \multirow[t]{3}{*}{0.15} & 0.94 & $0.23-3.86$ & 0.93 \\
\hline Penetrating & 23 & & 1.33 & \multirow[t]{2}{*}{$0.37-4.80$} & \multirow[t]{2}{*}{0.66} \\
\hline Nonstricturing/nonpenetrating & 18 & & 1 & & \\
\hline \multicolumn{6}{|l|}{ Anal disease } \\
\hline No & 17 & \multirow[t]{2}{*}{0.068} & 0.27 & \multirow[t]{2}{*}{$0.056-1.37$} & \multirow[t]{2}{*}{0.11} \\
\hline Yes & 52 & & 1 & & \\
\hline \multicolumn{6}{|l|}{ Switch after surgery } \\
\hline Yes & 16 & \multirow[t]{2}{*}{0.15} & 0.29 & \multirow[t]{2}{*}{$0.084-0.99$} & \multirow[t]{2}{*}{0.048} \\
\hline No & 53 & & 1 & & \\
\hline \multicolumn{6}{|l|}{ Concomitant thiopurine } \\
\hline Yes & 29 & \multirow[t]{2}{*}{0.17} & 0.32 & \multirow[t]{2}{*}{$0.11-0.94$} & \multirow[t]{2}{*}{0.039} \\
\hline No & 40 & & 1 & & \\
\hline \multicolumn{6}{|l|}{ Reason for the switch } \\
\hline Intolerance & 17 & \multirow[t]{3}{*}{0.71} & 0.53 & $0.15-1.80$ & 0.31 \\
\hline Primary failure & 7 & & 0.51 & \multirow[t]{2}{*}{$0.14-1.81$} & \multirow[t]{2}{*}{0.30} \\
\hline Secondary failure & 45 & & 1 & & \\
\hline
\end{tabular}

${ }^{\mathrm{a}}$ Log-rank test. ${ }^{\mathrm{b}}$ Cox proportional hazards model.

concomitant thiopurine, when used with biologics, reduces anti-drug antibodies to the first biologic and contributes to the better outcomes of the second biologic. In this study, a multivariate analysis showed that concomitant thiopurine was not identified as a clinical factor that affects the longterm prognosis. We suspected that this might be due to the small number of patients, and further studies are needed to clarify this aspect.

We have also previously revealed that the cumulative surgery-free survival rate of the same group of Japanese patients with CD decreased each year [16]. In the present study, the same tendency was observed in patients who switched their biologics. As expected, the cumulative surgery-free survival rate of patients who switched biologics was lower than that of biologic-naive patients. This result is thought to be associated with the reduction of the cumulative relapse-free survival rate.

Regarding the clinical factors that affect the relapsefree survival rate, the multivariate analysis in this study revealed that the ileal type, stricturing and penetrating types, switch after surgery, and intolerance were clinical factors that reduced the risk of recurrence. The switch after surgery and intolerance are thought to reduce the risk for recurrence, as surgery can be performed to reset the bowel condition with resection of the complicated bowel, such as stricturing and penetrating, decreasing the effect of biologics. A meta-analysis revealed that intolerance cases had a lower recurrence rate than primary and secondary failure cases [18]. However, it seems to be paradoxical that the ileal type and stricturing and fistula types reduce the risk of recurrence. We assumed that $\mathrm{CD}$ patients with ileal lesions including stricturing and penetrating lesions would possibly develop bowel complications which would ultimately require bowel resection. Such patients with CD who presented with reset bowel lesions, which could decrease the effect of biologics, showed favorable results. Therefore, the results that were obtained appeared to be paradoxical. Furthermore, a hypothesis that these disease behaviors might not always be consistent during the study period could be another reason for the 
controversial result. Therefore, when treating patients in whom biologics showed lesser effects, we should clarify the reason for switching biologics and need to investigate bowel complications, including strictures, fistulae, and abscesses, which require surgical intestinal resection.

In this study, considering the clinical factors that affect the surgery-free survival rate, the multivariate analysis revealed that the switch after surgery and concomitant thiopurine were clinical factors that reduced the risk of recurrence. Surgical intestinal resection before switching biologics was thought to reduce the risk of resurgery as it resets bowel complications. Moreover, in this study, concomitant thiopurine did not improve the relapse-free survival rate but rather improved the surgery-free rate. This discrepancy might be due to the small number of patients in this study.

This study has several limitations. First, several important clinical factors including the CD activity index and smoking habits were not known due to the retrospective design. Second, the sample size was relatively small for evaluation of other clinical factors that affect the longterm prognosis after switching biologics. Third, measurement of drug levels and anti-drug antibodies is not covered by insurance in Japan. Therefore, we were not able to measure the drug levels and anti-drug antibodies in daily clinical practice.

In conclusion, we should clarify the reason for switching and investigate bowel complications before switching biologics. Surgical reset of bowel complications, including stricturing and penetrating lesions, could reduce the risk of recurrence after switching biologics. Concomitant thiopurine administration might reduce the risk for bowel surgery after switching biologics.

\section{Acknowledgement}

We gratefully acknowledge the work of past and present members of our laboratory.

\section{Statement of Ethics}

Subjects gave their written informed consent and the study protocol was approved by the institute's committee on human research.

\section{Disclosure Statement}

The authors have no conflict of interests to declare.

\section{Funding Sources}

There are no financial sources to declare.

\section{Author Contributions}

Rintaro Moroi: acquisition, stastical analysis, interpretation of the data, and writing of this paper; Hisashi Shiga: acquisition, interpretation of the data, and revision of this paper; Katsuya Endo: study design, acquisition, statistical analysis, and interpretation of the data; Katsutoshi Yamamoto: acquisition, statistical analysis, and interpretation of the data; Masatake Kuroha, Yoshitaka Kinouchi, and Yoshitake Kanazawa: data acquisition; Yoichi Kakuta: acquisition and interpretation of the data; and Atsushi Masamune: revision of this paper. All of the authors read and approved the final version of this article.

\section{References}

1 Baumgart DC, Sandborn WJ. Crohn's disease. Lancet. 2012 Nov;380(9853):1590-605.

2 Hanauer SB, Feagan BG, Lichtenstein GR, Mayer LF, Schreiber S, Colombel JF, et al.; ACCENT I Study Group. Maintenance infliximab for Crohn's disease: the ACCENT I randomised trial. Lancet. 2002 May;359(9317): $1541-9$.

3 Hanauer SB, Sandborn WJ, Rutgeerts P, Fedorak RN, Lukas M, MacIntosh D, et al. Human anti-tumor necrosis factor monoclonal antibody (adalimumab) in Crohn's disease: the CLASSIC-I trial. Gastroenterology. 2006 Feb;130(2):323-33.

4 Sands BE, Blank MA, Patel K, van Deventer SJ: Long-term treatment of rectovaginal fistulas in Crohn's disease: response to infliximab in the ACCENT II Study. Clin Gastroenterol Hepatol. 2004;2:912-20.
5 Colombel JF, Sandborn WJ, Rutgeerts P, Enns R, Hanauer SB, Panaccione R, et al. Adalimumab for maintenance of clinical response and remission in patients with Crohn's disease: the CHARM trial. Gastroenterology. 2007 Jan;132(1):52-65.

6 Eshuis EJ, Peters CP, van Bodegraven AA, Bartelsman JF, Bemelman W, Fockens P, et al. Ten years of infliximab for Crohn's disease: outcome in 469 patients from 2 tertiary referral centers. Inflamm Bowel Dis. 2013 Jul; 19(8):1622-30.

7 Stein DJ, Ananthakrishnan AN, Issa M, Williams JB, Beaulieu DB, Zadvornova Y, et al. Impact of prior irregular infliximab dosing on performance of long-term infliximab maintenance therapy in Crohn's disease. Inflamm Bowel Dis. 2010 Jul;16(7): 1173-9.
8 Sprakes MB, Ford AC, Warren L, Greer D, Hamlin J. Efficacy, tolerability, and predictors of response to infliximab therapy for Crohn's disease: a large single centre experience. J Crohn's Colitis. 2012 Mar;6(2):14353.

9 Bouguen G, Trouilloud I, Siproudhis L, Oussalah A, Bigard MA, Bretagne JF, et al. Longterm outcome of non-fistulizing (ulcers, stricture) perianal Crohn's disease in patients treated with infliximab. Aliment Pharmacol Ther. 2009 Oct;30(7):749-56.

10 Schnitzler F, Fidder H, Ferrante M, Noman M, Arijs I, Van Assche G, et al. Long-term outcome of treatment with infliximab in 614 patients with Crohn's disease: results from a single-centre cohort. Gut. 2009 Apr;58(4): 492-500. 
11 Orlando A, Renna S, Mocciaro F, Cappello M, Giunta M, Mendolaro M, Mazza M, Rizzuto G, Orlando E, Affronti M, Dimarco M, Di Mitri R, Craxi A, Cottone M: Six year adalimumab efficacy in steroid-dependent Crohn's disease patients: a prospective single-center real life study. Dig Liver Dis. 2016;48:131417.

12 Billioud V, Sandborn WJ, Peyrin-Biroulet L. Loss of response and need for adalimumab dose intensification in Crohn's disease: a systematic review. Am J Gastroenterol. 2011 Apr;106(4):674-84.

13 Gisbert JP, Panés J. Loss of response and requirement of infliximab dose intensification in Crohn's disease: a review. Am J Gastroenterol. 2009 Mar;104(3):760-7.

14 Harper JW, Sinanan MN, Zisman TL. Increased body mass index is associated with earlier time to loss of response to infliximab in patients with inflammatory bowel disease. Inflamm Bowel Dis. 2013 Sep;19(10):211824.

15 Doecke JD, Hartnell F, Bampton P, Bell S, Mahy G, Grover Z, et al.; Australian and New Zealand Inflammatory Bowel Disease Consortium. Infliximab vs. adalimumab in Crohn's disease: results from 327 patients in an Australian and New Zealand observational cohort study. Aliment Pharmacol Ther. 2017 Feb;45(4):542-52.

16 Moroi R, Endo K, Yamamoto K, Naito T, Onodera M, Kuroha M, et al. Long-term prognosis of Japanese patients with biologicnaive Crohn's disease treated with anti-tumor necrosis factor-alpha antibodies. Intest Res. 2019 Jan;17(1):94-106.
17 Ma C, Panaccione R, Heitman SJ, Devlin SM, Ghosh S, Kaplan GG. Systematic review: the short-term and long-term efficacy of adalimumab following discontinuation of infliximab. Aliment Pharmacol Ther. 2009 Nov; 30(10):977-86.

18 Gisbert JP, Marín AC, McNicholl AG, Chaparro M. Systematic review with meta-analysis: the efficacy of a second anti-TNF in patients with inflammatory bowel disease whose previous anti-TNF treatment has failed. Aliment Pharmacol Ther. 2015 Apr;41(7):613-23.

19 Ng SC, Shi HY, Hamidi N, Underwood FE, Tang W, Benchimol EI, et al. Worldwide incidence and prevalence of inflammatory bowel disease in the 21st century: a systematic review of population-based studies. Lancet. 2018 Dec;390(10114):2769-78.

20 Vegh Z, Kurti Z, Lakatos PL. Epidemiology of inflammatory bowel diseases from west to east. J Dig Dis. 2017 Feb;18(2):92-8.

21 Fuyuno Y, Yamazaki K, Takahashi A, Esaki M, Kawaguchi T, Takazoe M, et al. Genetic characteristics of inflammatory bowel disease in a Japanese population. J Gastroenterol. 2016 Jul;51(7):672-81.

22 Matsuoka K, Kobayashi T, Ueno F, Matsui T, Hirai F, Inoue N, et al. Evidence-based clinical practice guidelines for inflammatory bowel disease. J Gastroenterol. 2018 Mar;53(3):30553.

23 Mizoshita T, Tanida S, Ozeki K, Katano T, Shimura T, Mori Y, et al. Long-Term Clinical Remission in Biologically Naïve Crohn's Disease Patients with Adalimumab Therapy, Including Analyses of Switch from Adalimumab to Infliximab. Case Rep Gastroenterol. 2016 Jun;10(2):283-91.
24 Bartelds GM, Wijbrandts CA, Nurmohamed MT, Stapel S, Lems WF, Aarden L, et al. Antiinfliximab and anti-adalimumab antibodies in relation to response to adalimumab in infliximab switchers and anti-tumour necrosis factor naive patients: a cohort study. Ann Rheum Dis. 2010 May;69(5):817-21.

25 Frederiksen MT, Ainsworth MA, Brynskov J, Thomsen OO, Bendtzen K, Steenholdt C. Antibodies against infliximab are associated with de novo development of antibodies to adalimumab and therapeutic failure in infliximabto-adalimumab switchers with IBD. Inflamm Bowel Dis. 2014 Oct;20(10):1714-21.

26 Ben-Horin S, Yavzori M, Benhar I, Fudim E, Picard O, Ungar B, et al. Cross-immunogenicity: antibodies to infliximab in Remicadetreated patients with IBD similarly recognise the biosimilar Remsima. Gut. 2016 Jul;65(7): $1132-8$.

27 Nakase H, Motoya S, Matsumoto T, Watanabe $\mathrm{K}$, Hisamatsu T, Yoshimura N, et al.; DIAMOND study group. Significance of measurement of serum trough level and antidrug antibody of adalimumab as personalised pharmacokinetics in patients with Crohn's disease: a subanalysis of the DIAMOND trial. Aliment Pharmacol Ther. 2017 Nov;46(9): 873-82.

28 Colombel JF, Sandborn WJ, Reinisch W, Mantzaris GJ, Kornbluth A, Rachmilewitz D, et al.; SONIC Study Group. Infliximab, azathioprine, or combination therapy for Crohn's disease. N Engl J Med. 2010 Apr; 362(15):1383-95. 